\title{
Circumplex Scales of Interpersonal Values: Reliability, Validity, and Applicability to Interpersonal Problems and Personality Disorders
}

\author{
Kenneth D. Locke \\ Department of Psychology \\ University of Idaho
}

\begin{abstract}
Three studies describe the development, psychometric properties, and potential utility of a new self-report measure, the Circumplex Scales of Interpersonal Values (CSIV). The CSIV was designed to complement other interpersonal circumplex measures that assess interpersonal behavior by efficiently assessing a comprehensive set of agentic and communal values. The eight 8-item scales of the CSIV were shown to have good internal consistency and test-retest reliability and a circumplex structure. The CSIV showed convergent and discriminant validity with measures of interpersonal traits (the Bem Sex Role Inventory; Bem, 1974), interpersonal problems (the Inventory of Interpersonal Problems-Circumplex; Horowitz, 2000), implicit interpersonal motives (the Thematic Apperception Test; see Atkinson, 1958), and interpersonal goals (the Interpersonal Goals Inventory; Dryer \& Horowitz, 1997). Finally, the locations of the MCMI-III (Millon, 1994) personality disorder scales on the CSIV circumplex generally mirrored the locations of personality disorders on other interpersonal circumplex measures.
\end{abstract}

The interpersonal circumplex is a comprehensive but parsimonious structural model for representing interpersonal dispositions (Carson, 1969; Wiggins, 1979). The circumplex is typically defined with reference to the orthogonal dimensions of agency (dominance, power, status) and communion (friendliness, warmth, love; Carson, 1969; Foa, 1961; Kiesler, 1983; Leary, 1957; Wiggins, 1979). As Figure 1 shows, the circle is typically segmented into eight octants, each reflecting a particular blend of agency and communion. The interpersonal circumplex has been used to describe, organize, and compare interpersonal adjectives (e.g., Conte \& Plutchik, 1981; Wiggins, 1979), personality measures (e.g., Gurtman, 1997; Wiggins \& 


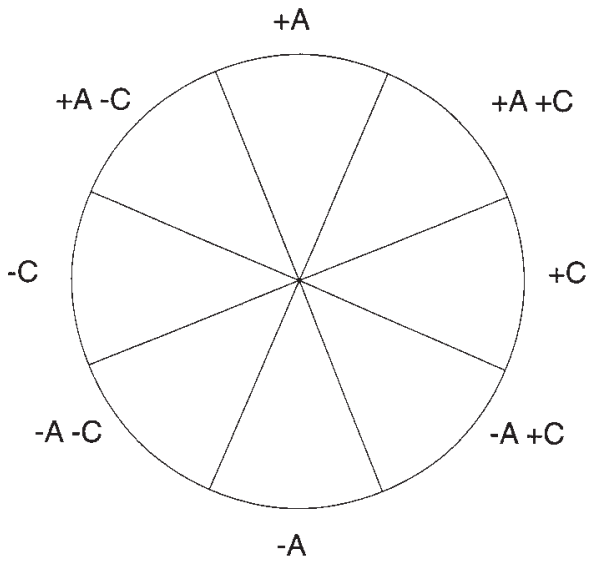

FIGURE 1 The interpersonal circumplex. $+\mathrm{A}=$ Agentic; $+\mathrm{A}+\mathrm{C}=$ Agentic and Communal; $+\mathrm{C}=\mathrm{Communal} ;-\mathrm{A}+\mathrm{C}=$ Submissive and Communal $;-\mathrm{A}=$ Submissive $;-\mathrm{A}-\mathrm{C}=$ Submissive and Separate $;-\mathrm{C}=$ Separate $; \mathrm{A}-\mathrm{C}=$ Agentic and Separate .

Broughton, 1991), interpersonal transactions (e.g., Horowitz et al., 1991; Tracey, 1994), interpersonal problems (e.g., Alden, Wiggins, \& Pincus, 1990; Gurtman, 1996), personality disorders (PDs; e.g., Matano \& Locke, 1995; Pincus \& Wiggins, 1990), and the interpersonal predictors of therapeutic outcomes (e.g., Eldredge, Locke, \& Horowitz, 1998; Horowitz, Rosenberg, \& Bartholemew, 1993).

Most interpersonal circumplex studies (including most of the studies cited previously) use either the Interpersonal Adjective Scales-Revised (IAS-R; Wiggins, 1995) or the Inventory of Interpersonal Problems-Circumplex (IIP-C; Alden et al., 1990; Horowitz, Rosenberg, Baer, Ureno, \& Villasenor, 1988). The IAS-R and IIP-C assess interpersonal traits and interpersonal problems, respectively. The purpose of this article is to introduce another interpersonal circumplex measure, the Circumplex Scales of Interpersonal Values (CSIV). ${ }^{1}$ The CSIV was designed to complement the IAS-R and IIP-C by assessing interpersonal values that may be associated with adaptive and maladaptive interpersonal behaviors. Experimental and naturalistic research have found links between values in general and behavior (Feather, 1982); the same should be true of interpersonal values and behaviors. For example, people who value others' approval are likely to seek others' approval, people who value being right are likely to be tenacious arguers, and so on.

Values generally are defined as preferences for certain outcomes or modes of conduct (Rokeach, 1973). Accordingly, in developing the CSIV, I conceptualized interpersonal values as preferences for certain interpersonal outcomes or modes of conduct. Modern value instruments typically operationalize values as ratings of the subjective importance of various outcomes or modes of conduct.

\footnotetext{
${ }^{1}$ Copies of the CSIV can be obtained from me or from http://www.its.uidaho.edu/klocke/csiv.htm
} 
For example, the Rokeach Value Survey (Rokeach, 1973) asks respondents to rank the importance of a list of values, the Pairwise Comparison Value Survey (Oishi, Schimmack, Diener, \& Suh, 1998) asks respondents to compare the importance of pairs of values, and the List of Values (Kahle, 1996) and the Schwartz Value Survey (Schwartz, 1992) ask respondents to rate the importance of value statements individually. Accordingly, the CSIV operationalizes interpersonal values by asking respondents to rate the importance of various interpersonal outcomes or modes of conduct. (The CSIV uses a rating rather than a ranking or comparison procedure because respondents typically find rating procedures less frustrating and more natural, and thus they respond faster.) What differentiates the CSIV from the value instruments cited previously is that whereas those instruments offer a broad sketch of both interpersonal and noninterpersonal values, the CSIV offers a more focused picture of interpersonal values in particular.

This article describes the development of the CSIV (Study 1); demonstrates its reliability, circular structure, and convergent and discriminant validity (Studies 1 and 2); and explores its utility for enriching our understanding of the interpersonal problems associated with PDs (Study 3).

\section{STUDY 1}

Study 1 had two purposes. The first was to describe the development of the CSIV, the internal consistency of the scales, and the pattern of scale intercorrelations. The second was to show the validity of the scales by comparing responses to the CSIV with responses to established measures of interpersonal traits, interpersonal problems, and interpersonal motives.

\section{Method}

\section{Participants}

University students $(N=588)$ participated for course credit in various undergraduate classes. All gave informed consent to participate. The participants ranged in age from 18 to 55 years $(M=21.0$ years, $S D=4.7)$; $65 \%$ were women. The CSIV was administered either alone $(n=124)$ or with the Bem Sex Role Inventory (BSRI; Bem, 1974; $n=84)$, the IIP-C $(n=181)$, or the Thematic Apperception Test (TAT; see Atkinson, 1958; $n=199$ ).

\section{Selection and Presentation of CSIV Items}

The original item pool consisted of 128 statements derived from two sources. First, statements that expressed an interpersonal value (e.g., "I could not bear to 
make a mistake in front of them") were collected from published and unpublished therapy transcripts. Second, "I" statements derived from other interpersonal inventories were added to ensure that the items would assess the entire interpersonal space. The items were administered with the following instructions:

For each item below, answer the following question: When I am in interpersonal situations (such as with close friends, with strangers, at work, at social gatherings, and so on), in general how important is it to me that I act or appear or am treated this way? Use the following rating scale: 0 (not important), 1 (mildly important), 2 (moderately important), 3 (very important), 4 (extremely important).

I modified all of the statements so that they had the following form: "When I am with him/her/them, it is [how important] that [I act or appear or am treated this way]." The following is an example of an item:

When I am with him/her/them, it is $[0,1,2,3,4]$ that they show me respect.

In half of the items, the self was the subject (e.g., "It is important that $I$ not make them angry"), and in the other half of the items, other people were the subject (e.g., "It is important that they not get angry with me").

\section{Measures}

BSRI. The BSRI (Bem, 1974) is a self-report inventory containing a list of 20 stereotypically masculine traits, 20 stereotypically feminine traits, and 20 filler items. The respondents indicate how well each item describes them on a scale ranging from 1 (never or almost never true) to 7 (always or almost always true). Wiggins and Holzmuller (1981) reported that after removing 3 items from the masculine scale (athletic, individualistic, masculine) and 4 items from the feminine scale (childlike, shy, flatterable, gullible), these two scales were excellent measures of Dominance (CSIV Agentic [+A]) and Nurturance (CSIV Communal [+C]), respectively. These modified scales were used in the analyses that follow.

TAT. The TAT was used to assess the interpersonal motives of power and intimacy. The TAT was administered in the standard group format in which participants had $5 \mathrm{~min}$ to write a story in response to each of six pictures (for details, see Smith, Feld, \& Franz, 1992). Each story was scored for power by three judges and for intimacy by two judges. Judges were trained using the coding manuals for power motivation (Winter, 1992b) and intimacy motivation (McAdams, 1992b). Winter (1992a) and McAdams (1992a) reviewed studies showing the validity of 
the power and intimacy scoring systems, respectively. The scoring systems involve scoring two or three basic imagery categories, and then, if power or intimacy imagery has been found, scoring a series of subcategories. Extensive experience with the TAT shows that scoring subcategories inevitably yields very skewed distributions without yielding significant changes in interjudge reliabilities or rank orderings of the participants. Judges, therefore, scored only the basic categories. Next, judges summed the scores for the six stories. The intraclass correlation coefficients for power and intimacy (treating judges as a random variable) were, respectively, .67 and .77. Because the reliabilities were adequate, I averaged the judges' scores for each participant. There was a small but significant negative relation between power and intimacy imagery, $r(197)=-.16, p=.01$.

IIP-C. The IIP-C (Horowitz, 2000) asks participants to rate how distressed they have been by each of 127 interpersonal problems on a 5-point scale ranging from 0 (not at all) to 4 (extremely). Each of the eight circumplex scales (Alden et al., 1990) contains eight items. The problems include both "things you find hard to do" and "things you do too much." Examples of items are "It is hard for me to feel close to other people" and "I am too independent."

\section{Results and Discussion}

\section{Factor Structure and Internal Consistency of the CSIV}

To create eight scales that conformed to a circumplex structure, I used a procedure used by previous investigators (e.g., Alden et al., 1990; Dryer \& Horowitz, 1997). First, participants' responses to the items were correlated with one another, and the matrix of intercorrelations was subjected to a principal components analysis (PCA). Plotting the items according to their loadings on the first two factors produced an approximation of the interpersonal circumplex. Within each octant of that space, I selected eight items on the basis of each item's communality and thematic content. Table 1 shows a description of the CSIV scales along with the Cronbach's alpha for each scale. ${ }^{2}$

\footnotetext{
${ }^{2}$ I originally intended to select for each octant 4 items in which the self was the subject ("I" items) and 4 items in which other people were the subject ("they" items). However, this was not possible for two reasons. First, the "I" items tended to have higher loadings than the "they" items. Thus, 37 of the final 64 items were "I" items. Second, whereas most of the items loading high on the cool-hostile side of the space were "I" items, most of the items loading high on the warm-friendly side of the space were "they" items. Thus, in the final scales, whereas 27 of the 32 items in the Agentic and Separate (+A-C), Separate $(-C)$, Submissive and Separate $(-A-C)$, and Submissive $(-A)$ octants were "I" items, only 10 of the 32 items in the Submissive and Communal $(-A+C),+C$, Agentic and Communal $(+A+C)$, and +A octants were "I" items.
} 
TABLE 1

Circumplex Scales of Interpersonal Values Scales and Reliability Data

\begin{tabular}{|c|c|c|c|}
\hline Scale & $\begin{array}{l}\text { When Interacting With Others, High } \\
\text { Scorers Report Valuing }\end{array}$ & $\begin{array}{l}\text { Sample Item: "It Is } \\
\text { Important That ..." }\end{array}$ & $\alpha$ \\
\hline$+\mathrm{A}$ & $\begin{array}{l}\text { Appearing confident, correct, and in } \\
\text { authority, and not letting others boss } \\
\text { them around. }\end{array}$ & $\begin{array}{l}\text { "They acknowledge when I } \\
\text { am right." }\end{array}$ & .76 \\
\hline$+\mathrm{A}-\mathrm{C}$ & $\begin{array}{l}\text { Appearing forceful, having the upper hand, } \\
\text { and avenging any attacks or insults. }\end{array}$ & "I keep the upper hand." & .82 \\
\hline$-\mathrm{C}$ & $\begin{array}{l}\text { Appearing cool and detached, being } \\
\text { guarded, and concealing their thoughts } \\
\text { and feelings. }\end{array}$ & $\begin{array}{l}\text { "They not know what I am } \\
\text { thinking or feeling." }\end{array}$ & .81 \\
\hline$-\mathrm{A}-\mathrm{C}$ & $\begin{array}{l}\text { Avoiding ridicule and rejection by } \\
\text { avoiding blunders and concealing their } \\
\text { positive feelings. }\end{array}$ & "I not say something stupid." & .84 \\
\hline$-\mathrm{A}$ & $\begin{array}{l}\text { Avoiding arguments and anger by going } \\
\text { along with what others want and expect. }\end{array}$ & "I not make them angry." & .82 \\
\hline$-\mathrm{A}+\mathrm{C}$ & $\begin{array}{l}\text { Getting others to like and approve of them } \\
\text { by putting others' needs first. }\end{array}$ & "They like me." & .85 \\
\hline$+\mathrm{C}$ & $\begin{array}{l}\text { Feeling connected with and genuinely } \\
\text { cared about and supported by others. }\end{array}$ & $\begin{array}{l}\text { "They show concern for how } \\
\text { I am feeling." }\end{array}$ & .86 \\
\hline$+\mathrm{A}+\mathrm{C}$ & $\begin{array}{l}\text { Expressing themselves openly, and being } \\
\text { heard, respected, and having an impact. }\end{array}$ & $\begin{array}{l}\text { "They respect what I have to } \\
\text { say." }\end{array}$ & .76 \\
\hline
\end{tabular}

Note. $\quad N=588 .+\mathrm{A}=$ Agentic $;+\mathrm{A}-\mathrm{C}=$ Agentic and Separate $;-\mathrm{C}=$ Separate $;-\mathrm{A}-\mathrm{C}=$ Submissive and Separate $;-\mathrm{A}=$ Submissive $;-\mathrm{A}+\mathrm{C}=$ Submissive and Communal $+\mathrm{C}=\mathrm{Communal} ;+\mathrm{A}+\mathrm{C}=$ Agentic and Communal. The sample items are those with the highest item-total correlation for that scale.

Table 2 shows the intercorrelations of the eight CSIV scales. The scale scores in these and subsequent analyses were ipsatized, that is, expressed as deviations from the participant's mean score across all of the scales. Ipsatizing is a common procedure when assessing or utilizing the circumplex properties of interpersonal measures (e.g., Alden et al., 1990; Soldz, Budman, Demby, \& Merry, 1993; Wiggins, Steiger, \& Gaelick, 1981). For each scale, the highest positive correlations were with adjacent octants and the highest negative correlation was with the polar opposite octant. Overall, the pattern of intercorrelations showed a circular ordering with no reversals. The intercorrelations of the eight scales were subjected to PCA. The first two factors explained $71.1 \%$ of the variance. Figure 2 shows that the loadings of the eight scales on the two factors conformed to a circumplex structure. The communalities ranged from .67 to .75 .

I conducted a formal test of whether the CSIV met the criteria for a circumplex model by means of a randomization test of hypothesized order relations (Hubert \& Arabie, 1987), using the program RANDALL (Tracey, 1997). The randomization test is more flexible than other confirmatory techniques and can test models of any type of similarity matrix (Tracey, 2000). Perfect fit to a circular model requires that correlations of adjacent scales on the circle (e.g., $+\mathrm{A}$ and $+\mathrm{A}+\mathrm{C})$ exceed corre- 
lations of scales two octants apart (e.g., $+\mathrm{A}$ and $+\mathrm{C}$ ), which in turn exceed those of scales three octants apart (e.g., $+\mathrm{A}$ and $-\mathrm{A}+\mathrm{C}$ ), which in turn exceed those of scales opposite on the circle (e.g., + A and -A). In total, a circular model makes 288 predictions about the relative magnitudes of correlations among eight octant scales. (Correlations assumed to be equal, e.g., the relations of $+\mathrm{A}$ and $-\mathrm{A}$ vs. $+\mathrm{C}$ and $-\mathrm{C}$, are not compared.) RANDALL computes the number of these predictions

TABLE 2

Intercorrelations Among the CSIV Scales

\begin{tabular}{|c|c|c|c|c|c|c|c|c|}
\hline Scale & 1 & 2 & 3 & 4 & 5 & 6 & 7 & 8 \\
\hline 1. $+\mathrm{A}$ & 1.00 & & & & & & & \\
\hline 2. $+\mathrm{A}-\mathrm{C}$ & .33 & 1.00 & & & & & & \\
\hline 3. $-\mathrm{C}$ & -.08 & .41 & 1.00 & & & & & \\
\hline 4. $-\mathrm{A}-\mathrm{C}$ & -.45 & -.07 & .33 & 1.00 & & & & \\
\hline 5. $-\mathrm{A}$ & -.62 & -.45 & -.12 & .33 & 1.00 & & & \\
\hline 6. $-\mathrm{A}+\mathrm{C}$ & -.39 & -.65 & -.61 & -.17 & .33 & 1.00 & & \\
\hline 7. $+\mathrm{C}$ & .00 & -.46 & -.67 & -.52 & -.15 & .47 & 1.00 & \\
\hline 8. $+\mathrm{A}+\mathrm{C}$ & .38 & -.20 & -.42 & -.61 & -.42 & .07 & .46 & 1.00 \\
\hline
\end{tabular}

Note. $N=588 . \mathrm{CSIV}=$ Circumplex Scales of Interpersonal Values; $+\mathrm{A}=$ Agentic $;+\mathrm{A}-\mathrm{C}=$ Agentic and Separate $;-\mathrm{C}=$ Separate $;-\mathrm{A}-\mathrm{C}=$ Submissive and Separate $;-\mathrm{A}=$ Submissive $;-\mathrm{A}+\mathrm{C}=$ Submissive and Communal; $+\mathrm{C}=\mathrm{Communal} ;+\mathrm{A}+\mathrm{C}=$ Agentic and Communal. The greatest negative correlation for each CSIV scale is shown in bold.

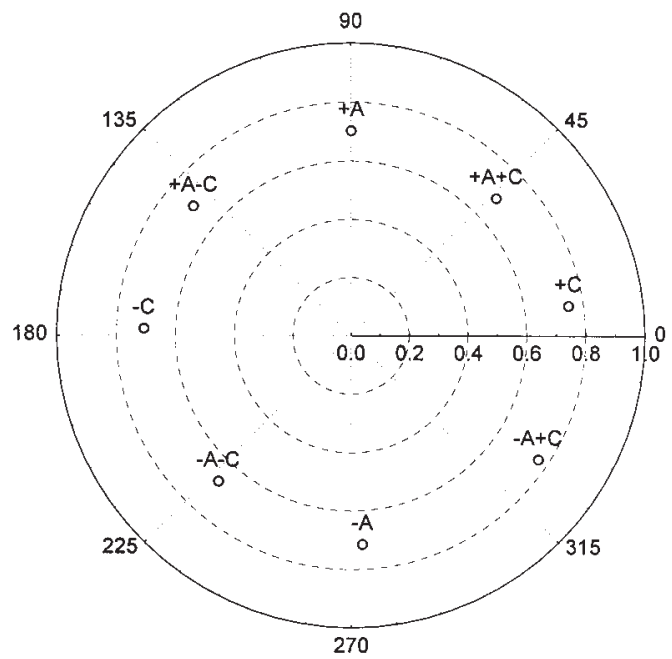

FIGURE 2 Circumplex structure of the Circumplex Scales of Interpersonal Values $(N=588)$, with the solution rotated so Agentic $(+\mathrm{A})$ is at $90^{\circ} .+\mathrm{A}+\mathrm{C}=$ Agentic and Communal; $+\mathrm{C}=\mathrm{Com}-$ munal $;-\mathrm{A}+\mathrm{C}=$ Submissive and Communal $;-\mathrm{A}=$ Submissive $;-\mathrm{A}-\mathrm{C}=$ Submissive and Separate $;-\mathrm{C}=$ Separate $;+\mathrm{A}-\mathrm{C}=$ Agentic and Separate . 
met in a particular sample, a correspondence index (CI; Hubert \& Arabie, 1987) equal to the proportion of predictions met minus the proportion violated and the exact probability that the observed fit would occur by chance (by comparing the observed fit with the distribution of fit obtained from all possible permutations of the rows and columns of the correlation matrix). The CI can range from -1.0 (all predictions violated) to 0.0 (chance or $50 \%$ of predictions met) to 1.0 (perfect fit). Using RANDALL to test the fit of a circular model to the CSIV data in Table 2, 287 of the 288 predictions were met $(\mathrm{CI}>.99, p<.001)$, indicating nearly perfect conformity.

\section{Correlations With the BSRI}

To the extent that interpersonal behaviors reflect interpersonal values, the CSIV should be related to measures of interpersonal traits such as the BSRI. Thus, CSIV scales loading positively on the communion dimension should be positively related to the BSRI Nurturance scale and those loading negatively on communion should be negatively related to BSRI Nurturance. Similarly, CSIV scales loading positively on the agency dimension should be positively related to BSRI Dominance and those loading negatively on agency should be negatively related to BSRI Dominance. Table 3 shows that the correlations between the scales of the CSIV and the BSRI conformed to these predictions. For example, BSRI Dominance had its highest positive correlation with CSIV +A and its highest negative correlation with CSIV $-\mathrm{A}$ and was not related to CSIV + C or - C. Similarly, BSRI Nurturance had its highest positive correlation with $+\mathrm{C}$ and its highest negative correlation with $-\mathrm{C}$ and was not related to $\mathrm{CSIV}+\mathrm{A}$ or $-\mathrm{A}$.

\section{Correlations With the TAT}

Table 3 shows the correlations between the needs for intimacy and power (as assessed by the TAT) and the CSIV. In general, the correlations between self-report measures (which assess the explicit self-concept) and thematic measures such as the TAT (which measure implicit motives) are very weak or not significant (McClelland, Koestner, \& Weinberger, 1992). Thus, although the correlations were weak, the existence of significant correlations is meaningful and cannot be attributed to shared method variance.

Need for intimacy correlated positively with $+\mathrm{C}$. Thus, people whose TAT stories contain intimacy imagery tend to report that they value interpersonal connection and support. Need for power correlated positively with $+\mathrm{A}-\mathrm{C}$ and $-\mathrm{C}$ and negatively with $-\mathrm{A}$. Thus, people whose TAT stories contain power imagery tend to report that they value being forceful and aggressive to assert or defend them- 
TABLE 3

Pearson Correlation Coefficients Between the CSIV and the BSRI (Dominance and Nurturance) and TAT (Power and Intimacy)

\begin{tabular}{lccccc}
\hline & \multicolumn{3}{c}{ BSRI $^{\mathrm{a}}$} & & \multicolumn{2}{c}{ TAT $^{\mathrm{b}}$} \\
\cline { 2 - 3 } \cline { 5 - 6 } CSIV Scale & Dominance & Nurturance & & Power & Intimacy \\
\hline +A & .38 & -.07 & .09 & -.05 \\
$+\mathrm{A}-\mathrm{C}$ & .17 & -.36 & .24 & -.09 \\
$-\mathrm{C}$ & .05 & -.48 & .21 & -.14 \\
$-\mathrm{A}-\mathrm{C}$ & -.19 & -.17 & -.06 & -.09 \\
$-\mathrm{A}$ & -.32 & .06 & -.22 & .02 \\
$-\mathrm{A}+\mathrm{C}$ & -.15 & .33 & -.16 & .13 \\
$+\mathrm{C}$ & -.08 & .37 & -.15 & .21 \\
$+\mathrm{A}+\mathrm{C}$ & .18 & .36 & .02 & .01 \\
\hline
\end{tabular}

Note. $\mathrm{CSIV}=$ Circumplex Scales of Interpersonal Values; $\mathrm{BSRI}=\mathrm{Bem}$ Sex Role Inventory; $\mathrm{TAT}=$ Thematic Apperception Test $+\mathrm{A}=$ Agentic $;+\mathrm{A}-\mathrm{C}=$ Agentic and Separate $;-\mathrm{C}=$ Separate $;-\mathrm{A}-\mathrm{C}=$ Submissive and Separate $;-\mathrm{A}=$ Submissive $;-\mathrm{A}+\mathrm{C}=$ Submissive and Communal $;+\mathrm{C}=$ Communal; $+\mathrm{A}+\mathrm{C}=$ Agentic and Communal.

${ }^{\mathrm{a}} n=84$, so $r \mathrm{~s}>.27, p<.01 . \mathrm{b}_{n}=199$, so $r \mathrm{~s}>.18, p<.01$.

selves. In general, need for intimacy aligned with the $+\mathrm{C}$ vector, but need for power aligned with the $+\mathrm{A}-\mathrm{C}$ vector. This finding accords with the earlier finding that the needs for power and intimacy are negatively correlated and suggests that the need for power typically assessed by the TAT (Winter, 1992a, 1992b) is the need for hostile power.

\section{Structural Convergence of the CSIV and IIP-C Circumplex}

To the extent that interpersonal problems reflect interpersonal values, the CSIV should be related to measures of interpersonal problems such as the IIP-C. Table 4 shows the correlations between the scales of the CSIV and the IIP-C. The diagonal of the matrix shows that the highest positive correlation for a CSIV scale was with the theoretically appropriate IIP-C counterpart in all but one instance. The one exception was the CSIV +A scale, which correlated highest with the IIP-C +A-C scale. The circumplex model also requires that a given scale correlate highly negatively with the scale directly opposite on the circle. The highest or second highest negative correlation for a CSIV scale was with the polar opposite IIP-C scale. The results for all scales conformed to the expected pattern of decreasing then increasing coefficients with no reversals.

To formally test the structural convergence of the two instruments, I followed the procedure used by Wagner, Kiesler, and Schmidt (1995). The 16 octants scores 
TABLE 4

Pearson Correlation Coefficients Between the Scales of the CSIV and the IIP-C

\begin{tabular}{lcccccccr}
\hline & \multicolumn{7}{c}{ IIP-C Scale } \\
\cline { 2 - 9 } & $\begin{array}{l}P A \\
\text { CSIV Scale }\end{array}$ & $\begin{array}{c}B C \\
(+A)\end{array}$ & $\begin{array}{c}D E \\
(+A-C)\end{array}$ & $\begin{array}{c}F G \\
(-C)\end{array}$ & $\begin{array}{c}\text { HI } \\
(-A-C)\end{array}$ & $\begin{array}{c}J K \\
(-A)\end{array}$ & $\begin{array}{c}L M \\
(+C)\end{array}$ & $\begin{array}{c}\text { NO } \\
(+A+C)\end{array}$ \\
\hline$+\mathrm{A}$ & .29 & $\mathbf{. 3 2}$ & .01 & -.11 & -.38 & -.23 & .00 & .20 \\
$+\mathrm{A}-\mathrm{C}$ & .40 & $\mathbf{. 5 6}$ & .24 & -.03 & -.50 & -.43 & -.24 & .11 \\
$-\mathrm{C}$ & .08 & .25 &. $\mathbf{3 9}$ & .16 & -.08 & -.30 & -.27 & -.23 \\
$-\mathrm{A}-\mathrm{C}$ & -.13 & -.04 & .23 & $\mathbf{. 3 4}$ & .13 & -.03 & -.25 & -.31 \\
$-\mathrm{A}$ & -.35 & -.43 & -.19 & .07 &. $\mathbf{4 5}$ & .42 & .10 & -.16 \\
$-\mathrm{A}+\mathrm{C}$ & -.24 & -.45 & -.31 & -.06 & .33 &. $\mathbf{4 2}$ & .24 & .01 \\
$+\mathrm{C}$ & -.10 & -.22 & -.31 & -.21 & .11 & .21 & $\mathbf{. 3 1}$ & .24 \\
$+\mathrm{A}+\mathrm{C}$ & .14 & .08 & -.10 & -.25 & -.15 & -.08 & .18 & $\mathbf{. 2 3}$ \\
\hline
\end{tabular}

Note. $n=181$. CSIV $=$ Circumplex Scales of Interpersonal Values; IIP-C = Inventory of Interpersonal Problems-Circumplex; $+\mathrm{A}=$ Agentic $;+\mathrm{A}-\mathrm{C}=$ Agentic and Separate $;-\mathrm{C}=$ Separate $;-\mathrm{A}-\mathrm{C}=$ Submissive and Separate $;-\mathrm{A}=$ Submissive $;-\mathrm{A}+\mathrm{C}=$ Submissive and Communal $;+\mathrm{C}=\mathrm{Communal}$; $+\mathrm{A}+\mathrm{C}=$ Agentic and Communal. For correlations greater than $.19, p<.01$. Correlations along the diagonal are for corresponding CSIV and IIP-C scales. For each CSIV scale, the highest correlation is shown in bold.

(from both measures) were subjected to a PCA and plotted on the first two factors. The degree of convergence was computed as the mean angular displacement (MAD) in degrees between corresponding octant scales, and the significance of this observed convergence was tested as $\chi^{2}=4 n\left[\cos (\mathrm{MAD} / 2)^{2}\right]$, where $n$ is the number of pairs of scales being compared. The MAD was $20.2^{\circ}$, yielding a $\chi^{2}(16)$ of $31.02, p<.01$. Thus, the null hypothesis was rejected, indicating significant structural convergence between the IIP-C and the CSIV.

Two inventories can show convergence simply because they are redundant with one another. To ensure that the CSIV was offering an isomorphic but not redundant instrument, I examined the relations between the individual items of the two inventories. In a few cases, the contents of correlated items were similar. The most striking example was the pair of items "I put other people's needs before my own too much" (from the IIP-C) and "It is important that I put their needs before mine" (from the CSIV). However, in the majority of cases, the contents of the correlated items were distinct. For example, the strongest correlate of the IIP-C item "I fight with other people too much" was the CSIV item "It is important that I attack back when I am attacked" $(r=.23)$. The strongest correlate of the IIP-C "It is hard for me to ask other people to get together socially with me" was the CSIV "It is important that I not expose myself to the possibility of rejection" ( $r=.34)$. The strongest correlate of the IIP-C "It is hard for me to let other people know what I want" was the CSIV "It is important that they not get angry with me" $(r=.35)$. Finally, the 
strongest correlate of the IIP-C "It is hard for me to take instructions from people who have authority over me" was the CSIV "It is important that I am the one in charge" $(r=.26)$. Of course, it is not at all surprising that wanting to attack back gets one into fights, that wanting to avoid rejection makes one reluctant to make social invitations, and so on. However, these relations are not simply semantic and show that the CSIV adds a distinct level of analysis.

\section{STUDY 2}

In Study 1, the data used to test the fit of a circumplex model was the same data used in developing the CSIV. Thus, the first aim of Study 2 was to test if the circumplex properties of the CSIV would replicate in a different sample. The second aim was to assess the test-retest reliability of the CSIV. The third aim was to examine the relation of the CSIV to the recently developed Interpersonal Goals Inventory (IGI; Dryer \& Horowitz, 1997). The IGI is similar to the CSIV in that it assesses the degree to which respondents consider it important to meet interpersonal goals associated with each octant of the circumplex (e.g., "to be assertive with the other person"). However, the CSIV differs from the IGI in two important ways. First, the IGI was designed to assess goals that are specific to the context of working on a task, whereas the CSIV was designed to assess values that are consistent across contexts. Second, the development of the CSIV scales involved a larger pool of items and a larger sample of respondents. Because of these similarities and differences, I expected that the CSIV would show significant structural convergence with the IGI while also showing superior circumplex properties.

\section{Method}

University students $(N=471)$ participated for course credit in various undergraduate classes. All gave informed consent to participate. The participants ranged in age from 17 to 46 years ( $M=19.6$ years, $S D=3.4) ; 61 \%$ were women. The CSIV was embedded in a large packet of tests. The other tests were unrelated to this study, except in the case of 248 participants whose test packets included the IGI. A random sample of 69 participants completed the CSIV a second time. The intertest interval was approximately 2 weeks $(M=15.35$ days, $S D=7.82$, range $=5-37)$.

\section{Results}

The results for the CSIV were similar to those in Study 1. For each scale, the highest positive correlations were with adjacent octants and the highest negative correla- 
tion was with the polar opposite octant. The intercorrelations of the eight scales were subjected to a PCA. The first two factors explained $71.4 \%$ of the variance. The communalities ranged from .67 to .76. As in Study 1, the conformance of the CSIV to a circular model was tested using a randomization test of hypothesized order relations. Even in this smaller sample, 283 of the 288 predictions were met $(\mathrm{CI}=.97$, $p<.001$ ), again indicating nearly perfect conformity.

I assessed the stability of the CSIV over time in the sample of participants who completed the CSIV twice by computing Pearson correlation coefficients. The test-retest coefficients were .84 for the $+\mathrm{A}$ scale, .88 for $+\mathrm{A}-\mathrm{C}, .84$ for $-\mathrm{C}, .85$ for $-\mathrm{A}-\mathrm{C}, .76$ for $-\mathrm{A}, .81$ for $-\mathrm{A}+\mathrm{C}, .86$ for $+\mathrm{C}$, and .78 for $+\mathrm{A}+\mathrm{C}$. All of the coefficients were significant at the .001 level.

Table 5 shows the correlations between the scales of the CSIV and the IGI. For all CSIV scales, the highest positive correlation was within one octant of the corresponding IGI scale and the highest negative correlation was within one octant of the polar opposite IGI scale. Although the results for all scales generally conformed to the expected pattern of decreasing then increasing coefficients, there were some reversals. To formally test the structural convergence of the two instruments, I followed the procedure used in Study 1 to compare the CSIV and IIP-C. The octants scores from both measures were subjected to a PCA and plotted on the first two factors. The MAD between corresponding octant scales was $28.3^{\circ}, \chi^{2}(16)$ $=28.3, p<.05$. Thus, the convergence of the CSIV and IGI was significant but less than that of the CSIV and IIP-C. The poorer convergence with the IGI appears to be due to the less adequate fit of the IGI to a circumplex structure. When I sub-

TABLE 5

Pearson Correlation Coefficients Between the Scales of the CSIV and the IGI

\begin{tabular}{|c|c|c|c|c|c|c|c|c|}
\hline \multirow[b]{2}{*}{ CSIV Scale } & \multicolumn{8}{|c|}{ IGI Scale } \\
\hline & $\begin{array}{c}P A \\
(+A)\end{array}$ & $\begin{array}{c}B C \\
(+A-C)\end{array}$ & $\begin{array}{l}D E \\
(-C)\end{array}$ & $\begin{array}{c}F G \\
(-A-C)\end{array}$ & $\begin{array}{c}H I \\
(-A)\end{array}$ & $\begin{array}{c}J K \\
(-A+C)\end{array}$ & $\begin{array}{c}L M \\
(+C)\end{array}$ & $\begin{array}{c}N O \\
(+A+C)\end{array}$ \\
\hline$+\mathrm{A}$ & .31 & .16 & -.00 & -.19 & -.30 & -.10 & -.04 & .28 \\
\hline$+\mathrm{A}-\mathrm{C}$ & .14 & .13 & .33 & .05 & -.38 & -.27 & -.19 & .20 \\
\hline$-\mathrm{C}$ & -.06 & .09 & .28 & .29 & -.24 & -.16 & -.29 & .01 \\
\hline$-\mathrm{A}-\mathrm{C}$ & -.22 & -.06 & .12 & .31 & .08 & -.01 & -.18 & -.17 \\
\hline$-\mathrm{A}$ & -.25 & -.11 & -.07 & .10 & .36 & .14 & .04 & -.29 \\
\hline$-\mathrm{A}+\mathrm{C}$ & -.16 & -.15 & -.24 & -.10 & .33 & .37 & .20 & -.25 \\
\hline$+\mathrm{C}$ & .06 & -.07 & -.23 & -.22 & .17 & .05 & .29 & .02 \\
\hline$+\mathrm{A}+\mathrm{C}$ & .21 & .00 & -.27 & -.32 & .04 & .03 & .23 & .21 \\
\hline
\end{tabular}

Note. $n=248$. CSIV = Circumplex Scales of Interpersonal Values; IGI = Interpersonal Goals Inventory; $+\mathrm{A}=$ Agentic $;+\mathrm{A}-\mathrm{C}=$ Agentic and Separate $;-\mathrm{C}=$ Separate $;-\mathrm{A}-\mathrm{C}=$ Submissive and Separate; $-\mathrm{A}=$ Submissive $;-\mathrm{A}+\mathrm{C}=$ Submissive and Communal $+\mathrm{C}=\mathrm{Communal} ;+\mathrm{A}+\mathrm{C}=$ Agentic and Communal. For correlations greater than $.15, p<.01$. Correlations along the diagonal are for corresponding CSIV and IGI scales. For each CSIV scale, the highest correlation is shown in bold. 
jected the CSIV and the IGI to separate PCAs (in each analysis using just the $n=$ 248 who took both inventories), the first two factors explained $72.2 \%$ of the variance in CSIV scores but only $51.3 \%$ of the variance in IGI scores. Applying the randomization test of circular structure, the CI was .91 for the CSIV but only .76 for the IGI.

\section{STUDY 3}

A constellation of personality traits so inflexible and maladaptive as to cause significant subjective distress or impairment in functioning may be considered a PD. In the Diagnostic and Statistical Manual of Mental Disorders (4th ed. [DSM-IV]; American Psychiatric Association, 1994), the problems diagnostic of PDs are often interpersonal in nature. Four studies have empirically located PDs in the interpersonal space defined by the IAS-R or IIP-C. Using college students, Wiggins and Pincus (1989) and Pincus and Wiggins (1990) mapped the Minnesota Multiphasic Personality Inventory PD scales (Morey, Waugh, \& Blashfield, 1985) onto the IAS-R or IIP-C circumplex. Using clinical patients, Soldz et al. (1993) and Matano and Locke (1995) mapped the Millon Clinical Multiaxial Inventory (MCMI; Millon, 1983), the MCMI-II (Millon, 1987), or the Personality Disorder Examination (Loranger, 1988) onto the IIP-C circumplex. Despite the different samples and measures, there was agreement ( \pm 1 octant) in the placements of the PDs, with the exception of the borderline and compulsive PDs. To the extent that interpersonal problems reflect interpersonal values, I hypothesized that most PDs would also show clear projections onto the circumplex defined by the CSIV. Study 3 tested this hypothesis.

\section{Method}

The participants were 202 undergraduates ranging in age from 18 to 47 years $(M=$ 20.7 years, $S D=4.1) ; 64 \%$ were women. All gave informed consent to participate. The PD measure was the MCMI-III (Millon, 1994), a widely used 175-item true-false self-report inventory. It yields 24 clinical scales, but only the 10 scales assessing DSM-IV (1994) PDs were examined. For each scale, the MCMI-III uses normative data to convert raw scores to base-rate scores. The participants completed the CSIV and MCMI-III in large group settings.

\section{Results and Discussion}

Figure 3 shows the location of the PD scales on the circumplex defined by the CSIV. The coordinates for each scale were computed as follows: Agency $=.25 \times$ 


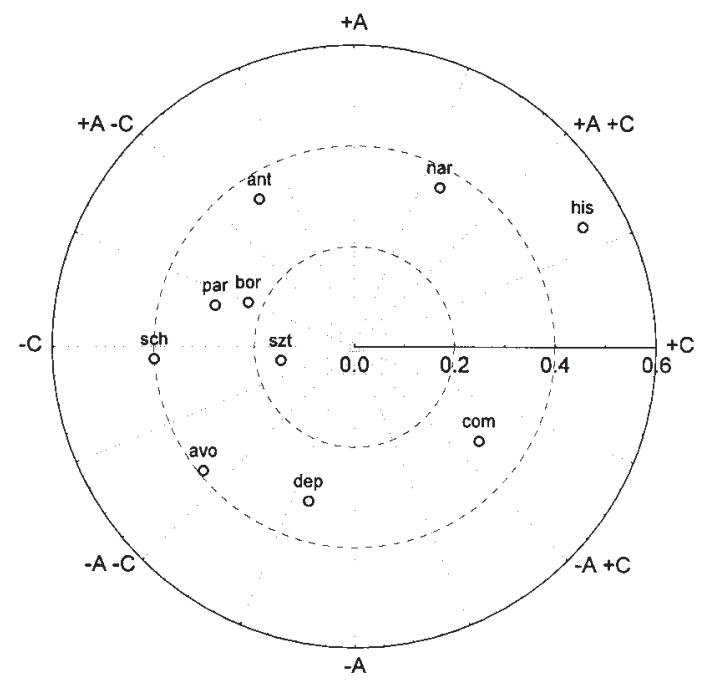

FIGURE 3 Locations of Millon Clinical Multiaxial Inventory-III personality disorder scales on the Circumplex Scales of Interpersonal Values circumplex $(n=202) .+\mathrm{A}=$ Agentic $+\mathrm{A}+\mathrm{C}=$ Agentic and $\mathrm{Communal} ;+\mathrm{C}=\mathrm{Communal} ;-\mathrm{A}+\mathrm{C}=$ Submissive and Communal $;-\mathrm{A}=$ Submis sive $;-\mathrm{A}-\mathrm{C}=$ Submissive and Separate $; \mathrm{C}=$ Separate $; \mathrm{A}-\mathrm{C}=$ Agentic and Separate , nar $=$ Nar cissistic $;$ his $=$ Histrionic $;$ com = Compulsive - Conforming $;$ dep = Dependent $;$ avo = Avoidant; szt $=$ Schizotypal sch $=$ Schizoid $;$ par $=$ Paranoid $;$ bor $=$ Borderline $;$ ant $=$ Antisocial .

$\Sigma\left(r_{i} \times \sin \Theta_{i}\right)$ and Communion $=.25 \times \Sigma\left(r_{i} \times \cos \Theta_{i}\right)$, where $r_{i}$ is the correlation of the scale with octant $i$ and $\Theta_{i}$ is the angle for octant $i$. Although the internal consistencies of MCMI scales tend to be lower in student than patient samples (Strack, 1993), my results generally agreed with the results of the studies cited previously that projected PDs onto the IIP-C or IAS-R circumplex. There were fewer PDs on the connecting side than on the separating side of the circumplex (three vs. seven). The Borderline and Schizotypal scales were associated with the least distinct or consistent interpersonal tendencies (i.e., the shortest vectors). The placements of the other scales were within one octant of their typical placements on the IIP-C or IAS-R circumplex, with the exception of the Compulsive-Conforming scale. Other researchers have found the compulsive PD either to be located in the $-\mathrm{A}-\mathrm{C}$ quadrant (Soldz et al., 1993) or to lack clear interpersonal correlates (Pincus \& Wiggins, 1990; Wiggins \& Pincus, 1989). However, this study and Matano and Locke (1995) located it in the $-\mathrm{A}+\mathrm{C}$ quadrant, reflecting a tendency to value deference to and approval from others.

As for the locations of the other scales, the Dependent scale projection was in the -A octant; thus, persons scoring high on this scale tend to report that it is especially important for them to avoid interpersonal conflict. The Avoidant projection 
was in the -A-C octant; it may be important for persons high on this scale to conceal themselves to avoid ridicule and rejection. The Schizoid and Schizotypal projections were in the $-\mathrm{C}$ octant; thus, it may also be important to persons high on these scales to feel separate and concealed but not necessarily to avoid ridicule or rejection. The Paranoid and Borderline projections were at the border of the $-\mathrm{C}$ and $+\mathrm{A}-\mathrm{C}$ octants; persons high on these scales may also value guarding themselves but in more forceful and aggressive ways. The Antisocial scale projection was on the +A side of the +A-C octant; persons high on this scale may also value forceful action but to obtain and maintain power. The Narcissistic and Histrionic projections were both in the $+\mathrm{A}+\mathrm{C}$ octant, with the former on the $+\mathrm{A}$ side and the latter on the $+\mathrm{C}$ side. Thus, persons high on the Narcissistic and Histrionic scales indicate that they want to be heard and have an impact, but whereas the former may be seeking status, the latter may be seeking connection.

Clarifying the interpersonal values associated with different problems may help therapists and patients refine the focus of therapeutic interventions. For example, avoidant persons are sometimes described as wanting connection while engaging in self-protective behaviors that defeat their goal. This model suggests that avoidant persons actually value avoiding social humiliations more than creating social connections. An appropriate intervention, then, may be to challenge the degree of importance placed on avoiding humiliation. Of course, when a pattern of behavior is so enduring and pervasive as to constitute $\mathrm{PD}$, no one value (or schema or other cognitive variable) will be the linchpin holding the pattern of behavior in place. Nonetheless, to the degree that avoidant persons feel less invested in avoiding humiliation, they should feel more empowered to take social risks. Similarly, challenging the value of avoiding conflict may help dependent persons resist social pressure, challenging the value of status and control may help narcissistic persons accept direction and criticism from others, and so on.

\section{GENERAL DISCUSSION}

This article describes the psychometric properties and potential utility of a new self-report measure of interpersonal values, the CSIV. The CSIV was designed to complement existing circumplex inventories that assess interpersonal behaviors. The scales of the CSIV were shown to have good internal and test-retest reliability and a circumplex structure. The CSIV also showed convergence with measures of adaptive interpersonal traits (the BSRI), maladaptive interpersonal traits (the IIP-C), implicit interpersonal motives (the TAT), and explicit interpersonal goals (the IGI). The CSIV shares the advantages of other interpersonal circumplex measures: It assesses the full range of traits (in this case, values) associated with differing levels of agency and communion, but its multiple scales can be summarized as a single point in the circumplex space (as in Figure 3). 
The CSIV may prove useful for studying a variety of interpersonal phenomena in addition to interpersonal traits, problems, and disorders. For example, consider interactions involving social support. Whereas some problems tend to elicit agentic social support (e.g., giving advice, facilitating action), other problems tend to elicit communal social support (e.g., expressing empathy and caring). People who value agency may be most comfortable giving and receiving agentic support, people who value communion may be most comfortable giving and receiving communal support, and people low in both agentic and communal values may be uncomfortable giving and receiving either type of support. Moreover, because people are most satisfied when the type of support they receive matches the type of problems they express (Horowitz et al., in press), social support transactions may be most satisfying among people with similar values. Using the CSIV to predict specific interpersonal behaviors like social support will be an important next step in demonstrating the validity and utility of the inventory.

Although values influence behaviors, there are also many other interacting determinants of behavior (Ajzen \& Fishbein, 1977). Moreover, values themselves can be shaped by behaviors (Bem, 1972) or may reflect less accessible cognitive structures such as relationship schemas (Baldwin, 1992). Nonetheless, values may often be a more convenient target of change interventions than either implicit assumptions or behaviors. In summary, interpersonal values are a potentially useful construct for understanding and enhancing interpersonal interactions, and this article suggests that the CSIV is a promising instrument for efficiently assessing a comprehensive range of interpersonal values.

\section{ACKNOWLEDGMENTS}

I am grateful to Patrick Gray, Frances Lepinski, Peggy Moody, Kira Perez, and Anna Storms for their help in coding the TATs and to Len Horowitz for comments on an earlier version of this article.

\section{REFERENCES}

Ajzen, I., \& Fishbein, M. (1977). Attitude-behavior relations: A theoretical analysis and review of empirical research. Psychological Bulletin, 84, 888-918.

Alden, L. E., Wiggins, J. S., \& Pincus, A. L. (1990). Construction of circumplex scales for the Inventory of Interpersonal Problems. Journal of Personality Assessment, 55, 521-536.

American Psychiatric Association. (1994). Diagnostic and statistical manual of mental disorders (4th ed.). Washington, DC: Author.

Atkinson, J. W. (Ed.). (1958). Motives in fantasy, action, and society. Princeton, NJ: Van Nostrand.

Baldwin, M. W. (1992). Relational schemas and the processing of social information. Psychological Bulletin, 112, 461-484. 
Bem, D. (1972). Self-perception theory. In L. Berkowitz (Ed.), Advances in experimental social psychology (Vol. 6, pp. 1-62). New York: Academic.

Bem, S. L. (1974). The measurement of psychological androgyny. Journal of Counseling and Clinical Psychology, 42, 155-162.

Carson, R. C. (1969). Interaction concepts of personality. Chicago: Aldine.

Conte, H. R., \& Plutchik, R. (1981). A circumplex model for interpersonal personality traits. Journal of Personality and Social Psychology, 40, 701-711.

Dryer, D. C., \& Horowitz, L. M. (1997). When do opposites attract? Interpersonal complementarity versus similarity. Journal of Personality and Social Psychology, 72, 592-603.

Eldredge, K. L., Locke, K. D., \& Horowitz, L. M. (1998). Patterns of interpersonal problems associated with binge eating disorder. International Journal of Eating Disorders, 23, 383-389.

Feather, N. T. (1982). Human values and the prediction of action: An expectancy-valence analysis. In N. T. Feather (Ed.), Expectations and actions: Expectancy-value models in psychology (pp. 263-289). Hillsdale, NJ: Lawrence Erlbaum Associates, Inc.

Foa, U. G. (1961). Convergences in the analysis of the structure of interpersonal behavior. Psychological Review, 68, 341-355.

Gurtman, M. B. (1996). Interpersonal problems and the psychotherapy context. The construct validity of the Inventory of Interpersonal Problems. Psychological Assessment, 8, 241-255.

Gurtman, M. B. (1997). Studying personality traits: The circular way. In R. Plutchik \& H. R. Conte (Eds.), Circumplex models of personality and emotions (pp. 347-384). Washington, DC: American Psychological Association.

Horowitz, L. M. (2000). Inventory of Interpersonal Problems manual. San Antonio, TX: Psychological Corporation.

Horowitz, L. M., Krasnoperova, E. N., Tatar, D. G., Person, E. A., Hansen, M. B., Galvin, K. L., \& Nelson, K. L. (in press). The way to console depends on the goal: Experimental studies of social support. Journal of Experimental Social Psychology.

Horowitz, L. M., Locke, K. D., Morse, M. B., Waikar, S. V., Dryer, D. C., Tarnow, E., \& Ghannam, J. (1991). Self-derogations and interpersonal theory. Journal of Personality and Social Psychology, 61, 68-79.

Horowitz, L. M., Rosenberg, S. E., Baer, B. A., Ureno, G., \& Villasenor, V. S. (1988). Inventory of Interpersonal Problems: Psychometric properties and clinical applications. Journal of Consulting and Clinical Psychology, 56, 885-892.

Horowitz, L. M., Rosenberg, S. E., \& Bartholemew, K. (1993). Interpersonal problems, attachment styles, and outcome in brief dynamic psychotherapy. Journal of Consulting and Clinical Psychology, 61, 549-560.

Hubert, L., \& Arabie, P. (1987). Evaluating order hypotheses within proximity matrices. Psychological Bulletin, 102, 172-178.

Kahle, L. R. (1996). Social values and consumer behavior: Research from the list of values. In C. Seligman, J. M. Olson, \& M. P. Zanna (Eds.), The psychology of values: The Ontario symposium (Vol. 8, pp. 135-151). Mahwah, NJ: Lawrence Erlbaum Associates, Inc.

Kiesler, D. J. (1983). The 1982 interpersonal circle: A taxonomy for complementarity in human transactions. Psychological Review, 90, 185-214.

Leary, T. (1957). Interpersonal diagnosis of personality. New York: Ronald.

Loranger, A. W. (1988). Personality Disorder Examination (PDE) manual. Yonkers, NY: DV Communications.

Matano, R., \& Locke, K. D. (1995). Personality disorder scales as predictors of interpersonal problems of alcoholics. Journal of Personality Disorders, 9, 62-67.

McAdams, D. P. (1992a). The intimacy motive. In C. P. Smith (Ed.), Handbook of thematic content analysis (pp. 224-228). New York: Cambridge University Press.

McAdams, D. P. (1992b). The intimacy motive scoring system. In C. P. Smith (Ed.), Handbook of thematic content analysis (pp. 229-253). New York: Cambridge University Press. 
McClelland, D. C., Koestner, R., \& Weinberger, J. (1992). How do self-attributed and implicit motives differ? In C. P. Smith (Ed.), Handbook of thematic content analysis (pp. 49-72). New York: Cambridge University Press.

Millon, T. (1983). Millon Clinical Multiaxial Inventory manual (3rd ed.). Minneapolis, MN: National Computer Systems.

Millon, T. (1987). Manual for the Millon Clinical Multiaxial Inventory-II. Minneapolis, MN: National Computer Systems.

Millon, T. (1994). Manual for the Millon Clinical Multiaxial Inventory-III. Minneapolis, MN: National Computer Systems.

Morey, L. C., Waugh, M. H., \& Blashfield, R. K. (1985). MMPI scales for DSM-III personality disorders: Their derivation and correlates. Journal of Personality Assessment, 49, 245-251.

Oishi, S., Schimmack, U., Diener, E., Suh, E. M. (1998). The measurement of values and individualism-collectivism. Personality and Social Psychology Bulletin, 24, 1177-1189.

Pincus, A. L., \& Wiggins, J. S. (1990). Interpersonal problems and conceptions of personality disorders. Journal of Personality Disorders, 4, 342-352.

Rokeach, M. (1973). The nature of human values. New York: Free Press.

Schwartz, S. H. (1992). Universals in the content and structure of values: Theoretical advances and empirical tests in 20 countries. In M. Zanna (Ed.), Advances in experimental social psychology (Vol. 25, pp. 1-65). Orlando, FL: Academic.

Smith, C. P., Feld, S. C., \& Franz, C. E. (1992). Methodological considerations: Steps in research employing content analysis systems. In C. P. Smith (Ed.), Handbook of thematic content analysis (pp. 515-536). New York: Cambridge University Press.

Soldz, S., Budman, S., Demby, A., \& Merry, J. (1993). Representation of personality disorders in a circumplex and five-factor space: Explorations with a clinical sample. Psychological Assessment, 5, $41-52$.

Strack, S. (1993). Measuring Millon's personality styles in normal adults. In R. J. Craig (Ed.), The Millon Clinical Multiaxial Inventory: A clinical research information synthesis (pp. 253-278). Hillsdale, NJ: Lawrence Erlbaum Associates, Inc.

Tracey, T. J. (1994). An examination of the complementarity of interpersonal behavior. Journal of Personality and Social Psychology, 67, 864-878.

Tracey, T. J. (1997). RANDALL: A Microsoft FORTRAN program for a randomization test of hypothesized order relations. Educational and Psychological Measurement, 57, 164-168.

Tracey, T. J. (2000). Analysis of circumplex models. In H. E. A. Tinsley \& S. Brown (Eds.), Handbook of applied multivariate statistics and mathematical modeling (pp. 641-664). San Diego: Academic.

Wagner, C. C., Kiesler, D. J., \& Schmidt, J. A. (1995). Assessing the interpersonal transaction cycle: Convergence of action and reaction interpersonal circumplex measures. Journal of Personality and Social Psychology, 69, 938-949.

Wiggins, J. S. (1979). A psychological taxonomy of trait-descriptive terms: The interpersonal domain. Journal of Personality and Social Psychology, 33, 409-420.

Wiggins, J. S. (1995). Interpersonal Adjective Scales: Professional manual. Odessa, FL: Psychological Assessment Resources.

Wiggins, J. S., \& Broughton, R. (1991). A geometric taxonomy of personality scales. European Journal of Personality, 5, 343-365.

Wiggins, J. S., \& Holzmuller, A. (1981). Further evidence on androgyny and interpersonal flexibility. Journal of Research in Personality, 15, 67-80.

Wiggins, J. S., \& Pincus, A. L. (1989). Conceptions of personality disorders and dimensions of personality. Psychological Assessment, 1, 305-316.

Wiggins, J. S., Steiger, J. H., \& Gaelick, L. (1981). Evaluating circumplexity in personality data. Multivariate Behavioral Research, 16, 263-289. 
Winter, D. G. (1992a). Power motivation revisited. In C. P. Smith (Ed.), Handbook of thematic content analysis (pp. 301-310). New York: Cambridge University Press.

Winter, D. G. (1992b). A revised scoring system for the power motive. In C. P. Smith (Ed.), Handbook of thematic content analysis (pp. 311-324). New York: Cambridge University Press.

Kenneth D. Locke

Department of Psychology

University of Idaho

Moscow, ID 83844

E-mail: klocke@uidaho.edu

Received November 19, 1999

Revised January 25, 2000 
Copyright of Journal of Personality Assessment is the property of Lawrence Erlbaum Associates and its content may not be copied or emailed to multiple sites or posted to a listserv without the copyright holder's express written permission. However, users may print, download, or email articles for individual use. 